\title{
Effect of Cultivation Variables on Biomass Composition and Growth of Microalgae and Cyanobacteria
}

\author{
Alejandra Sánchez-Bayo ${ }^{1}$, Victoria Morales ${ }^{2}$, Rosalía Rodríguez ${ }^{1}$, Gemma Vicente ${ }^{1}$ and Luis \\ Fernando Bautista ${ }^{2, *}$ \\ 1 Department of Chemical, Energy and Mechanical Technology. ESCET, Universidad Rey Juan Carlos, \\ 28933, Móstoles, Madrid, Spain; alejandra.sanchezbayo@urjc.es (ASB), rosalia.rodriguez@urjc.es (RR), \\ gemma.vicente@urjc.es (GV) \\ 2 Department of Chemical and Environmental Technology. ESCET, Universidad Rey Juan Carlos, 28933, \\ Móstoles, Madrid, Spain; victoria.morales@urjc.es (VM), fernando.bautista@urjc.es (LFB) \\ * Correspondence: fernando.bautista@urjc.es; +34 914888501
}

\begin{abstract}
The purpose of this work is to define optimal growth conditions for batch culture of the cyanobacterium Arthrospira maxima and the microalgae Chlorella vulgaris, Isochrysis galbana and Nannochloropsis gaditana. Thus, we study the effect of three variables on algae growth: i.e., inoculum:culture medium ratio, light:darkness photoperiod and type of culture medium, including both synthetic media and wastewaters. The results showed that the initial inoculum volume did not affect the amount of biomass at the end of the growth (14 days), whereas an excess ( $18 \mathrm{~h}$ ) or defect $(6 \mathrm{~h})$ in the number of hours of light is determinant for its development. The contribution of nutrients from different culture media modified the growth of the different species. A. maxima was favoured in seawater enriched with Guillard's F/2 as well as C. vulgaris and $N$. gaditana but in fresh water medium. I. galbana had the greatest growth in the marine environment enriched with Walne's media. Nitrate was the limiting growth reagent at the end of the exponential phase of growth for $C$. vulgaris and N. gaditana, while iron was for A. maxima and I. galbana. All species demonstrated their capability to grow in effluents from a wastewater treatment plant and they efficiently consume nitrogen, especially the three microalgae species.
\end{abstract}

Keywords: microalgae; cyanobacteria; biomass composition; culture optimization; growth on wastewaters.

\section{Introduction}

Microalgae and cyanobacteria are photoautotrophic microorganisms that use inexpensive and widely available natural resources, such as $\mathrm{CO}_{2}, \mathrm{H}_{2} \mathrm{O}$ and inorganic salts, to transform radiant energy into valuable products contained in the biomass. These photosynthetic microorganisms are among the most promising new sources of energy, since they are renewable and neutral with respect to $\mathrm{CO}_{2}$ emissions. The $\mathrm{CO}_{2}$ emitted after their use corresponds to that fixed from atmosphere by microalgae, so that no net $\mathrm{CO}_{2}$ emission is produced. Although the number of different algae and cyanobacteria species in nature is unknown, conservative estimations give values above 70,000 of which more than 40,000 have been published [1]. Because of this enormous number of species, in this work we have selected four different microorganisms of representative genera.

Arthrospira maxima is a species belonging to the phylum of Cyanobacteria. These microorganisms are characterized for being able to perform photosynthesis and, traditionally, they have been grouped, alongside $A$. platensis, under the term Spirulina. Generally, they are arranged in multicellular filaments and have been found in tropical and subtropical waters of alkaline lakes containing high 
concentrations of carbonate, either in salt or fresh water [2]. The main advantage of these species is their high protein content, so that they are used as food supplements. They also present great benefits to human health due to their antioxidant properties, their role as activator of cell regeneration, and their positive effect on kidney and memory problems [3].

Chlorella vulgaris is a small, spherical microalga with a size of $5-10 \mu \mathrm{m}$, belonging to the family of Chlorellaceae. It has high protein content and a balanced amino acid composition, which means that it is widely employed for human feeding. Different studies also show the possible mixotrophic behavior of this species [4].

Nannochloropsis gaditana is a microalga with a small size, around $3 \mu \mathrm{m}$, and helical morphology. This microalga belongs to the Eustigmataceae family and the name of the genus, Nannochloropsis, derives from its small size. The species of this genus usually grow in salt water, although they have also been found in fresh and brackish waters [5]. The main use of this alga is the feeding of fish in aquaculture due to the high accumulation of pigments, such as xanthines, and of polyunsaturated lipids [6]. However, in recent years it has been used for the production of biofuels, such as biodiesel, due to its lipid accumulation potential [7].

The microalga Isochrysis galbana belongs to the family of Isochrysidaceae. It is a unicellular species with a brownish colour and it has two flagella, with sizes within the range 3-5 $\mu \mathrm{m}$. I. galbana is known to have good nutritional qualities, and it is used in aquaculture as food in the early larval stages of molluscs, fishes and crustaceans. It is characterised by its capability to accumulate polyunsaturated fatty acids, particularly omega-3 such as eicosapentaenoic (EPA) and docosahexaenoic (DHA). Currently, it is being used to study the immuno-modulation properties of some of its components [8].

Recently, these microorganisms have been studied to produce different biofuels such as biodiesel [9], bioethanol [10], biogas [11] and biohydrogen [12]. In these biofuel production process, the study of the cultivation stage is crucial to obtain a suitable microalga biomass for the production of biofuels. In this context, the growth of photosynthetic microalgae and cyanobacteria is governed by several factors, such as temperature, $\mathrm{CO}_{2}, \mathrm{pH}$, nutrients and light conditions, which should be optimized in photo-bioreactor systems for further industrial scale-up. Since light is the driving force of photosynthesis, it is the major abiotic parameter affecting cell metabolism. Photosynthetic organisms can be adapted to changes in light intensity and spectrum. Too much light may reduce microalgal productivity and have negative effects on the quality of biofuels, although photosynthetic organisms have evolved many strategies to protect themselves from photodamage. Light quality also has a substantial impact on cell metabolism [13], modulating the biomass composition of carbohydrates, lipids and proteins [14].

Photoperiod is a factor regulating cell division in asexual reproduction, which occurs during the light period, and it is accelerated under continuous illumination. Therefore, the photoperiod can be adjusted according to the objectives of the culture: a continuous lighting produces rapid growth, whilst a photoperiod alternating hours of light and darkness, like the solar photoperiod, maintains a normal and healthy growth. The short-term and long-term adaptations associated with balances in photosystem stoichiometry have been investigated in relation to the spectral characteristics of light [15].

It has been found that another key factor favouring microalga growth is the presence of micronutrients, such as vitamins, in the culture medium [16,17]. The axenic culture of microalgae demands a more stringent composition of nutrients in their cultivation medium. Therefore, special formulations of standard media such as the Walne [18] and Guillard's F/2 [19] media are normally used to produce microalga monoculture at laboratory scale. The sufficient supplement of nutrients for microalga growth is a key step to produce a bulk quantity of high quality microalgal biomass. Microalgae can grow in poor-quality or even polluted waters because these may contain some of the required nutrients. Therefore, municipal, industrial or agricultural wastewaters can be used as cultivation media while simultaneously act as a biological treatment to remove and recycle nitrogen and phosphorus from those streams [20-22]. 
In this work, we have studied the effect of three key variables on the growth of one cyanobacteria (A. maxima) and three microalgae (C. vulgaris, N. gaditana and I. galbana). First, we analysed the effect of the initial inoculum:culture medium ratio, the light photoperiod and the culture media composition for each microorganism. To complement the study of the optimal culture conditions, the experiments were scaled-up to a larger volume, measuring protein, carbohydrate and lipid composition of the biomass. Additionally, we studied the consumption of different nutrients and micronutrients during the growth stage and the results were evaluated in terms of dry biomass and cell concentration fitting the results to Monod growth kinetics. Aimed to test growth and nutrients depletion in wastewaters, cultivation of microalgae and cyanobacteria were also carried out using water from different processes of a wastewater treatment plant.

\section{Results and discussions}

This section may be divided by subheadings. It should provide a concise and precise description of the experimental results, their interpretation as well as the experimental conclusions that can be drawn.

\subsection{Analysis of variables to maximize the growth}

The inoculum:culture medium ratio was studied for all species at $25^{\circ} \mathrm{C}$ using synthetic seawater with Guillard's F/2 as a culture medium. As it can be seen in Fig. 1, there was no significant difference between the ratios studied at the stationary growth phase for each species. As cultures are reaching the end of the exponential phase, growth curves for different inoculum:culture medium ratios are approaching the same plateau value as observed for I. galbana cultivated in raceway ponds [8]. This may be due to the fact that biomass concentration was high enough to produce shadowing of the cells. Taking this into account, subsequent studies were performed using the lowest inoculum:culture medium ratio (5:45), since a low inoculum concentration decreases the costs without affecting the cellular reproduction time.

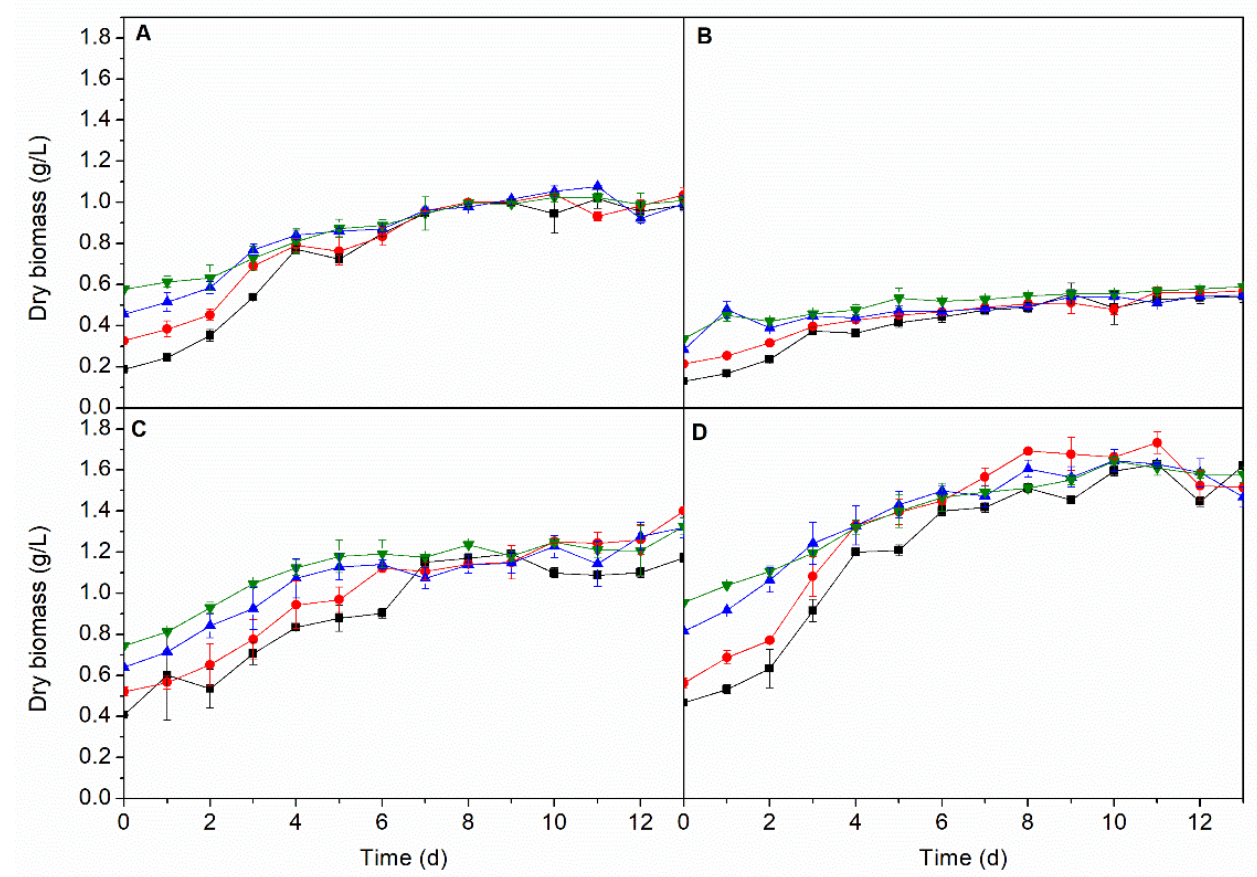

Figure 1. Growth of A. maxima (a), C. vulgaris (b), I. galbana (c) and N. gaditana (d) at different inoculum:culture medium ratio $(\bullet$ 5:45, $\bullet 10: 40, \Delta$ 15:35 and $\boldsymbol{\nabla}$ 20:30). 
Light is a key parameter for the growth of photosynthetic organisms to carry out their metabolic processes [23,24]. The light:darkness cycle determines the stage of development of the alga, i.e. cell division occurs during the light phase while the dark phase is used to accumulate reserves [25]. It has been shown that carbohydrates are mainly accumulated after light exposures above $8 \mathrm{~h}$ and, in the case of lipids, when the light period is longer than $12 \mathrm{~h}$ [26]. However, other studies have shown that the accumulation of lipids not only depends on the light phase, but also on other variables [27]. The results show how the growth of A. maxima, C. vulgaris and N. gaditana depends largely on the number of hours of light exposure. The light:darkness photoperiod was studied at three different values (Fig. 2). The two photoperiod with a larger number of light hours (18:6 and 12:12) increased production of biomass. In the case of A. maxima, the amount of dry biomass reached a maximum of around $1.0 \mathrm{~g} / \mathrm{L}$ after 8 days, regardless of the cycle used. However, there is a clear difference between the longest light cycle (18:6) and the shortest (6:18) where a long lag phase is observed in the latter. To a lesser extent, a similar behaviour was measured for $N$. gaditana, where a biomass production of $1.2 \mathrm{~g} / \mathrm{L}$ was reached after 13 days. In the case of $C$. vulgaris, the shortest light cycle (6:18) did not show the exponential growth phase and longer exposures to light resulted in biomass concentration of approximately $0.55 \mathrm{~g} / \mathrm{L}$. Growth of I. galbana seems to be somewhat insensitive to the light:darkness photoperiod because, in all cycles studied, the stationary phase was reached after 7 days. However, the amount of dry biomass was higher for the 18:6 and 12:12 light:darkness cycle (approximately, 1.3 $\mathrm{g} / \mathrm{L})$ compared to the $8: 16$ photoperiod $(1.0 \mathrm{~g} / \mathrm{L})$. Therefore, with the objective of achieving the optimum conditions of culture for each species, a 12:12 photoperiod was selected for further studies, since it provides the larger amount of biomass, it is closer to the natural photoperiod and, therefore, it needs lower energy supply to the process.

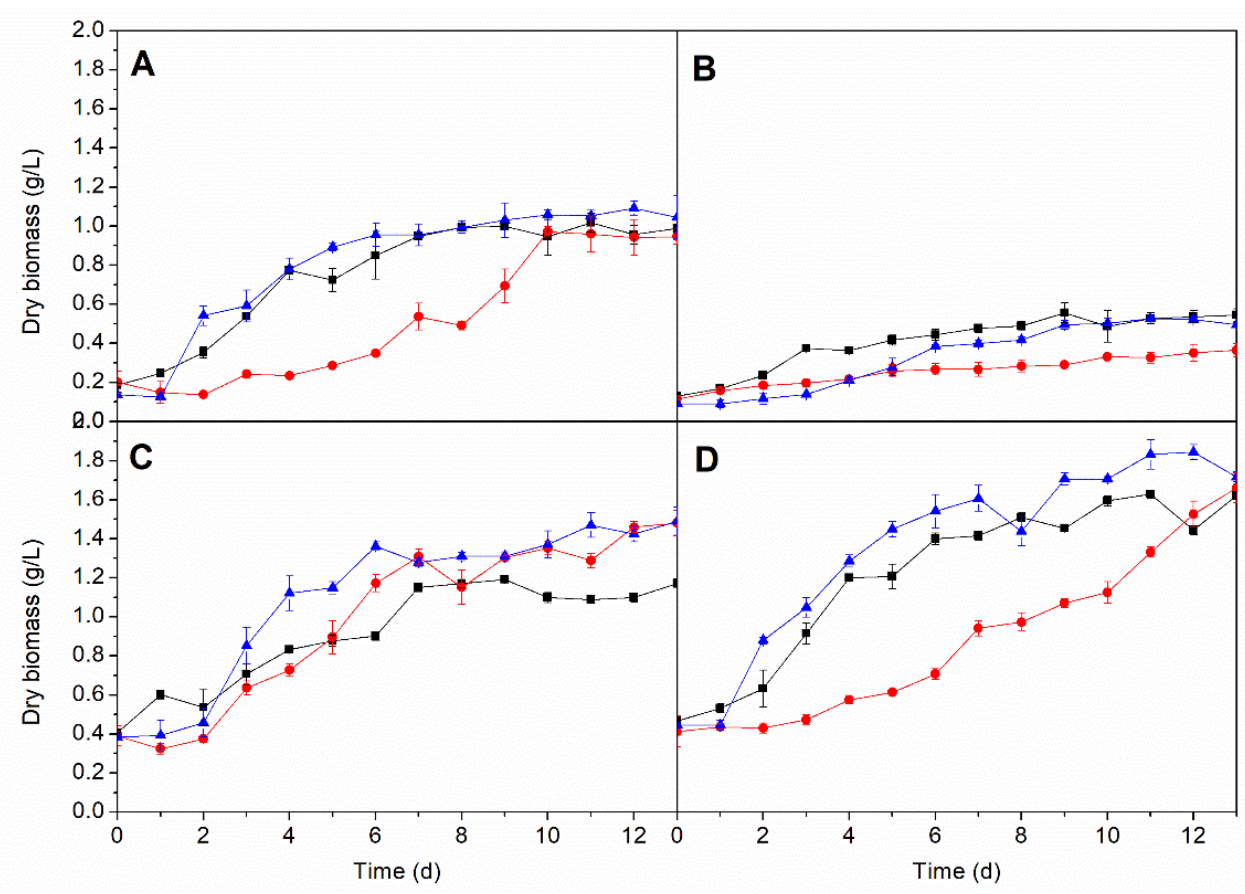

Figure 2. Growth of A. maxima (a), C. vulgaris (b), I. galbana (c) and N. gaditana (d) at different light:darkness photoperiod $(\bullet 6: 18, \boldsymbol{\bullet} 12: 12$ and $\triangle 18: 6 \mathrm{~h})$.

Three synthetic marine culture media were tested for growing all four species (Table 1): Guillard's F/2 (MC1), plain synthetic seawater (MC2) and Walne's (MC3). Additionally, C. vulgaris 
and N. gaditana were grown in two freshwater culture media: Guillard's F/2 (MC4) and Walne's (MC5). All the experiments were conducted with an inoculum:culture medium ratio of 5:45 and a photoperiod of 12:12 $\mathrm{h}$ previously selected for optimal conditions.

Table 1. Cultivation media

\begin{tabular}{ccl}
\hline Identification & \multicolumn{1}{c}{ Type } & \multicolumn{1}{c}{ Description } \\
\hline MC1 & Synthetic seawater & Guillard's F/2 medium \\
MC2 & Synthetic seawater & without additional nutrients \\
MC3 & Synthetic seawater & Walne's medium \\
MC4 & Freshwater & Guillard's F/2 medium \\
MC5 & Freshwater & Walne's medium \\
AD1 & Wastewater & After primary decanter \\
AD2 & Wastewater & After biological treatment \\
AD3 & Wastewater & After secondary decanter \\
\hline
\end{tabular}

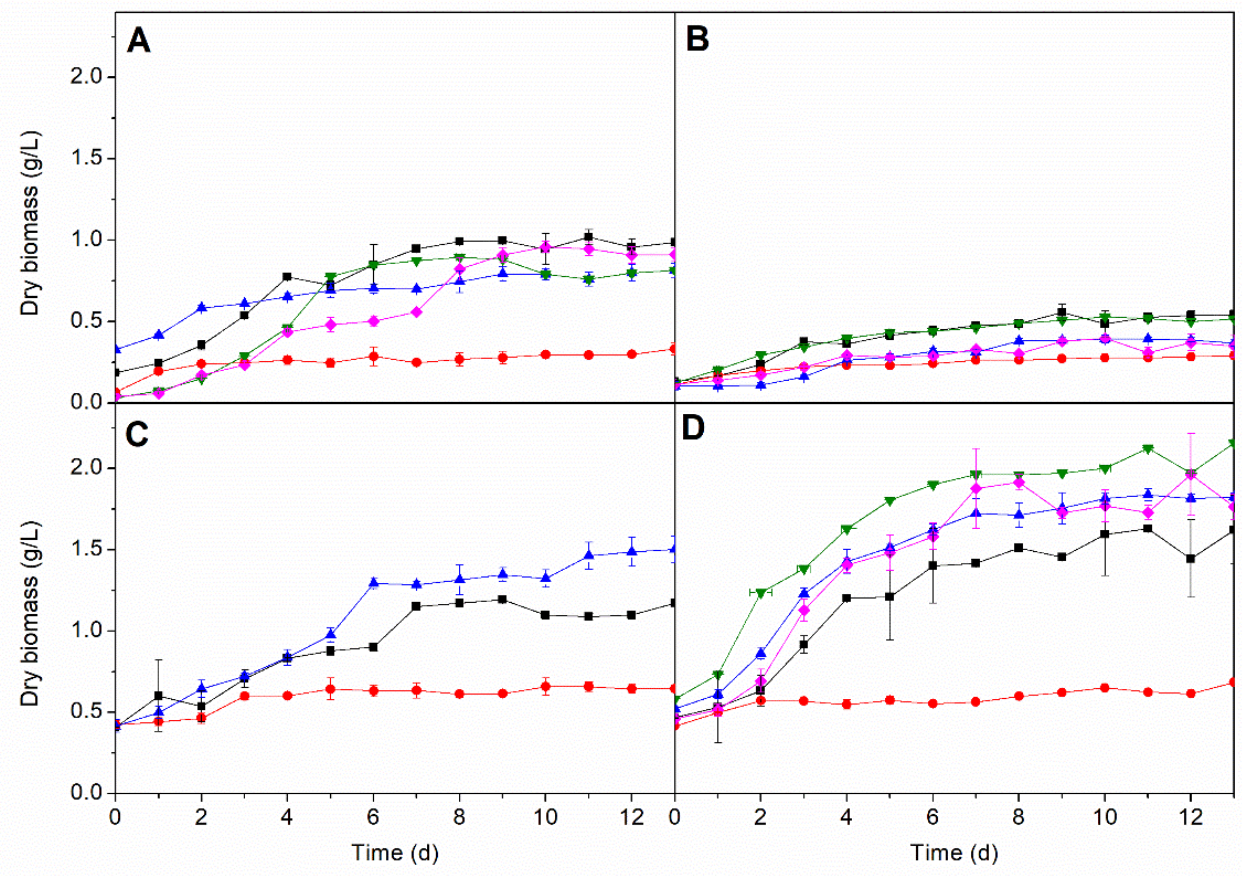

Figure 3. Growth of A. maxima (a), C. vulgaris (b), I. galbana (c) and N. gaditana (d) with different culture media $(-\mathrm{MC} 1, \bullet \mathrm{MC} 2, \triangle \mathrm{MC}, \diamond \mathrm{MC} 4$ and $\nabla \mathrm{MC})$.

The results obtained with the synthetic marine water (MC2) for all microalgae (Fig. 3) exhibit a very limited growth when compared to the other media, since MC2 is the only medium that was not enriched with vitamins and oligoelements. For A. maxima, the results showed that $\mathrm{MC} 1$ was the best culture medium. Under these conditions, cell growth yielded almost $1 \mathrm{~g} / \mathrm{L}$ of dry biomass. For $I$. galbana, MC3 produced even higher biomass production, reaching values of $1.4 \mathrm{~g} / \mathrm{L}$ of dry biomass. The microalgae growing in fresh water, i.e., C. vulgaris and N. gaditana, showed the best performance when cultured in the MC4 medium, with biomass concentrations of 0.5 and $1.8 \mathrm{~g} / \mathrm{L}$, respectively, 
although MC1 produced similar growth on C. vulgaris.

From the above results, the optimal conditions for the growth of A. maxima and I. galbana are salt water enriched with Guillard's F/2 (MC1) and Walne's (MC3) media, respectively. On the other hand, $N$. gaditana and C. vulgaris showed their best performance in fresh water enriched with Guillard's F/2 medium (MC4).

\subsection{Biomass composition}

At the optimum conditions selected for each species, growth was studied during 14 days in batch cultures, monitoring $\mathrm{pH}$, biomass composition and nutrient uptake. The $\mathrm{pH}$ is determinant for microalgae growth and all initial culture media had a $\mathrm{pH}$ value of 7.5. During cultivation, all species increased their $\mathrm{pH}$ over time, but that increase was mainly concentrated in the first part of the exponential phase (data not shown). This is associated with the fast $\mathrm{CO}_{2}$ consumption driving the $\mathrm{pH}$ towards alkaline values. The final $\mathrm{pH}$ was within the range 8-9 in all experiments, consistent with the values found in the literature [28], confirming that the media used provides a suitable $\mathrm{pH}$ environment for growth. The cultivation under extreme $\mathrm{pH}$ conditions, both acidic and basic, could allow the use of certain wastewater for the growth of the four species studied [29].

The major building blocks of biomass from microalgae and cyanobacteria are proteins, carbohydrates and lipids. Total biomass (Fig. 4), biomass composition (Tables 2-5) and the uptake of macro- (Fig. 4) and micronutrients (Fig. 5) were monitored during microbial growth at the optimum conditions selected for each species so far.

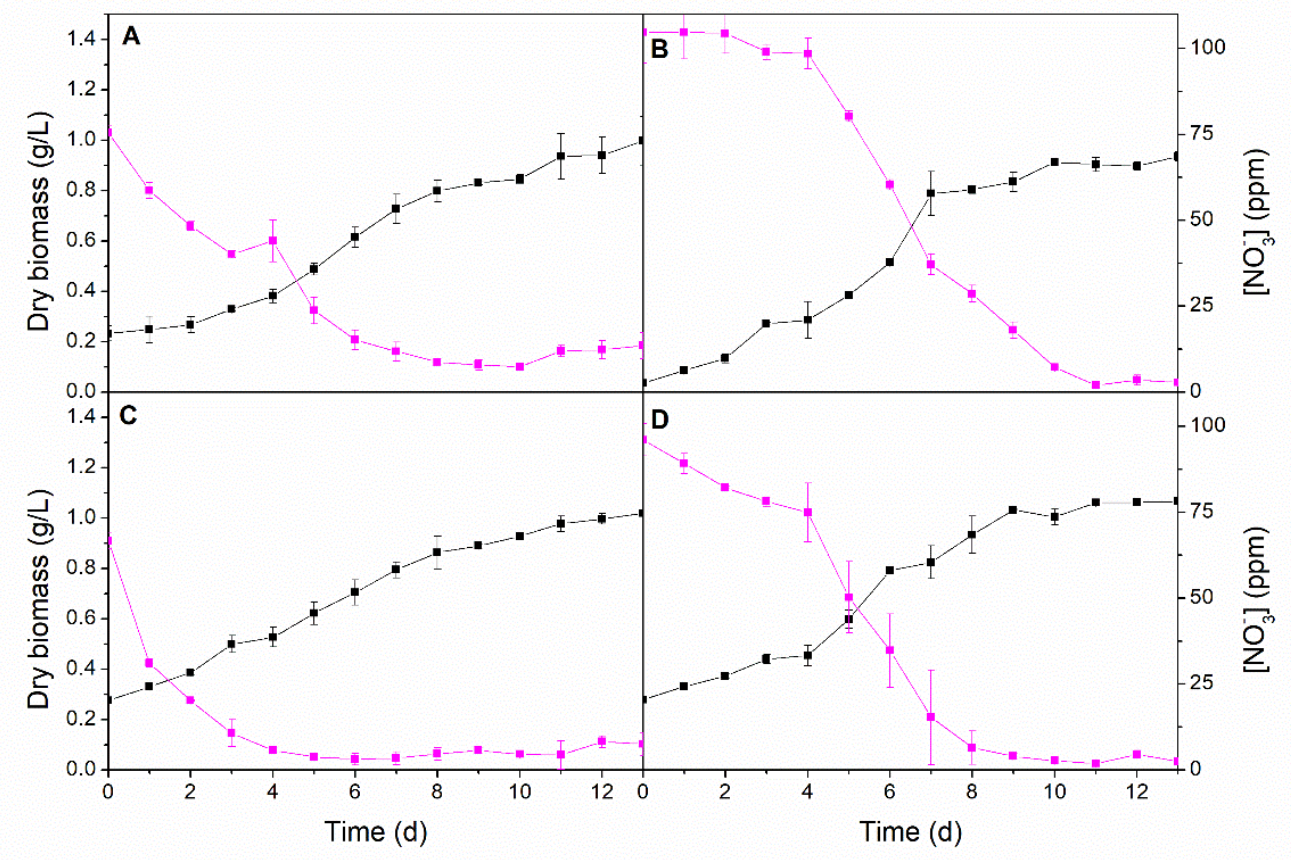

Figure 4. Growth (๘) and nitrate uptake (₫) of A. maxima (a), C. vulgaris (b), I. galbana (c) and N. gaditana (d). 
Table 2. Evolution of biomass composition (\%wt) of $A$. maxima with time

\begin{tabular}{cccccc}
\hline Time (d) & Lipids & Proteins & $\begin{array}{c}\text { Soluble } \\
\text { proteins }\end{array}$ & Carbohydrates & $\begin{array}{c}\text { Soluble } \\
\text { carbohydrates }\end{array}$ \\
\hline 1 & $1.54 \pm 0.01$ & $26.39 \pm 0.01$ & $0.19 \pm 0.01$ & $8.97 \pm 0.04$ & $1.5 \pm 0.3$ \\
2 & $1.60 \pm 0.02$ & $37.55 \pm 0.03$ & $0.54 \pm 0.01$ & $7.39 \pm 0.05$ & $1.6 \pm 0.1$ \\
3 & $2.00 \pm 0.01$ & $41.55 \pm 0.01$ & $1.18 \pm 0.01$ & $6.77 \pm 0.03$ & $2.00 \pm 0.08$ \\
4 & $2.29 \pm 0.01$ & $57.83 \pm 0.01$ & $2.44 \pm 0.01$ & $6.54 \pm 0.02$ & $2.29 \pm 0.01$ \\
5 & $2.08 \pm 0.01$ & $58.08 \pm 0.06$ & $2.72 \pm 0.01$ & $5.73 \pm 0.01$ & $2.08 \pm 0.06$ \\
6 & $2.34 \pm 0.01$ & $58.87 \pm 0.01$ & $3.48 \pm 0.01$ & $3.84 \pm 0.01$ & $2.34 \pm 0.08$ \\
7 & $2.43 \pm 0.02$ & $66.10 \pm 0.01$ & $3.45 \pm 0.01$ & $2.47 \pm 0.03$ & $2.4 \pm 0.6$ \\
\hline
\end{tabular}

Table 3. Evolution of biomass composition (\%wt) of C. vulgaris with time

\begin{tabular}{cccccc}
\hline $\begin{array}{c}\text { Time } \\
(\mathrm{d})\end{array}$ & Lipids & Proteins & Soluble proteins & Carbohydrates & $\begin{array}{c}\text { Soluble } \\
\text { carbohydrates }\end{array}$ \\
\hline 1 & $0.06 \pm 0.01$ & $32.51 \pm 0.02$ & $1.49 \pm 0.01$ & $6.23 \pm 0.01$ & $1.43 \pm 0.05$ \\
2 & $0.18 \pm 0.04$ & $51.24 \pm 0.01$ & $5.13 \pm 0.01$ & $7.21 \pm 0.01$ & $2.20 \pm 0.07$ \\
3 & $0.36 \pm 0.01$ & $56.98 \pm 0.03$ & $3.51 \pm 0.01$ & $7.54 \pm 0.01$ & $1.95 \pm 0.02$ \\
4 & $0.21 \pm 0.02$ & $45.77 \pm 0.32$ & $0.43 \pm 0.05$ & $5.54 \pm 0.04$ & $1.44 \pm 0.01$ \\
5 & $0.22 \pm 0.01$ & $30.35 \pm 0.85$ & $0.18 \pm 0.02$ & $6.06 \pm 0.11$ & $1.3 \pm 0.06$ \\
6 & $1.59 \pm 0.03$ & $23.18 \pm 0.12$ & $0.16 \pm 0.01$ & $5.72 \pm 0.13$ & $2.77 \pm 0.07$ \\
7 & $0.38 \pm 0.01$ & $13.49 \pm 0.01$ & $0.25 \pm 0.01$ & $7.71 \pm 0.09$ & $4.25 \pm 0.05$ \\
\hline
\end{tabular}

Protein content increases during the exponential growth phase for A. maxima (Table 2) and I. galbana (Table 4), reaching values of $66.10 \%$ and $76.58 \%$, respectively, in line with previous studies [30]. However, the accumulation of proteins attained a maximum before the exponential phase ended for C. vulgaris (Table 3) and N. gaditana (Table 5). Protein concentration started to decline after 3 days in C. vulgaris. The protein content reached by I. galbana (76.58\%) was significantly higher than that measured in Guillard's F/2 under continuous irradiance (45.31\%) [31]. This highlight the effect of the photoperiod on the composition of cell biomass. Of all protein content, soluble proteins are a small fraction of around $1-3 \%$, following a similar trend to that observed for total protein accumulation.

Carbohydrates in A. maxima (Table 2), I. galbana (Table 4) and N. gaditana (Table 5) showed decreasing values, from $6-9 \%$ to around $1 \%$, as growth progressed. This tendency is in agreement with the literature [31-33]. However, carbohydrate content in C. vulgaris (Table 4) was approximately constant during the exponential phase, with values ranging from 5 to $7 \%$. Other studies [32], where low-nitrate modified Zarrouk's medium [34] was used, describe higher carbohydrate accumulation in spirulina species, than those reached by A. maxima in the present work. This higher amount of carbohydrates can be explained by the larger nitrate limitation and the greater availability of carbon due to the presence of $\mathrm{HCO}_{3}$ - in Zarrouk's medium [35]. As seen in Tables 2-5, most carbohydrates are not soluble and, thus, must be complex since carbohydrates mainly form cell walls as celluloselike polymers and chitin-like glycans [36]. The lipid content during the first days of cultivation (Tables 2-5) was lower than the values usually reported as the maximum lipid concentration for these species because the synthesis and accumulation of lipids in microalgae and cyanobacteria increases at the 
end of the exponential growth phase, when nitrogen starvation is taking place (see, for example, [3739]).

Table 4. Evolution of biomass composition (\%wt) of I. galbana with time

\begin{tabular}{cccccc}
\hline $\begin{array}{c}\text { Time } \\
(\mathrm{d})\end{array}$ & Lipids & Proteins & Soluble proteins & Carbohydrates & $\begin{array}{c}\text { Soluble } \\
\text { carbohydrates }\end{array}$ \\
\hline 1 & $10.7 \pm 0.3$ & $24.99 \pm 0.03$ & $0.72 \pm 0.01$ & $7.95 \pm 0.01$ & $2.41 \pm 0.06$ \\
2 & $15.16 \pm 0.01$ & $34.17 \pm 0.02$ & $1.05 \pm 0.01$ & $6.40 \pm 0.01$ & $2.42 \pm 0.07$ \\
3 & $8.5 \pm 0.3$ & $35.17 \pm 0.05$ & $1.24 \pm 0.01$ & $6.96 \pm 0.01$ & $2.64 \pm 0.04$ \\
4 & $11.6 \pm 0.6$ & $52.55 \pm 0.08$ & $1.39 \pm 0.01$ & $6.41 \pm 0.01$ & $2.51 \pm 0.03$ \\
5 & $8.3 \pm 0.2$ & $58.1 \pm 0.1$ & $1.56 \pm 0.01$ & $2.96 \pm 0.02$ & $2.75 \pm 0.04$ \\
6 & $2.89 \pm 0.06$ & $68 \pm 0.02$ & $1.82 \pm 0.01$ & $2.88 \pm 0.01$ & $2.41 \pm 0.03$ \\
7 & $2.6 \pm 0.1$ & $76.58 \pm 0.01$ & $1.66 \pm 0.01$ & $2.78 \pm 0.01$ & $1.88 \pm 0.01$ \\
\hline
\end{tabular}

Table 5. Evolution of biomass composition (\%wt) of N. gaditana with time

\begin{tabular}{cccccc}
\hline $\begin{array}{c}\text { Time } \\
(\mathrm{d})\end{array}$ & Lipids & Proteins & $\begin{array}{c}\text { Soluble } \\
\text { proteins }\end{array}$ & Carbohydrates & $\begin{array}{c}\text { Soluble } \\
\text { carbohydrates }\end{array}$ \\
\hline 1 & $1.87 \pm 0.01$ & $19.95 \pm 0.01$ & $0.19 \pm 0.01$ & $6.52 \pm 0.01$ & $8.3 \pm 0.9$ \\
2 & $4.26 \pm 0.04$ & $15.64 \pm 0.03$ & $0.54 \pm 0.01$ & $6.37 \pm 0.01$ & $6.5 \pm 0.3$ \\
3 & $2.58 \pm 0.01$ & $43.46 \pm 0.01$ & $1.18 \pm 0.01$ & $4.43 \pm 0.03$ & $7.0 \pm 0.1$ \\
4 & $3.06 \pm 0.01$ & $42.75 \pm 0.02$ & $2.44 \pm 0.01$ & $3.71 \pm 0.01$ & $6.3 \pm 0.3$ \\
5 & $3.57 \pm 0.01$ & $45.78 \pm 0.01$ & $2.72 \pm 0.01$ & $2.90 \pm 0.01$ & $7 \pm 1$ \\
6 & $3.47 \pm 0.09$ & $41.55 \pm 0.04$ & $3.48 \pm 0.01$ & $2.03 \pm 0.02$ & $5 \pm 1$ \\
7 & $6.51 \pm 0.01$ & $41.79 \pm 0.01$ & $3.45 \pm 0.01$ & $0.94 \pm 0.04$ & $2.3 \pm 0.4$ \\
\hline
\end{tabular}

To contribute with a deeper knowledge of biomass composition, elemental analysis was also performed during the lag and the exponential phases of growth of all four species. Therefore, the amounts (\%wt, dry basis) of carbon, hydrogen, nitrogen, sulfur and oxygen were determined (Tables S2-S5). The carbon and hydrogen contents were high (20-53\% and 4-8\%, respectively). However, sulfur content was low (<3.5\%) and corresponds to sulfur amino acids (methionine and cysteine) in proteins.

One of the most important elements of study in the case of microalgae is the presence of nitrogen. Nitrogen is mainly contained in proteins and, to a lesser extent, in glycolipids from the cell walls and membranes, amino acids and sphingolipids. The nitrogen content is, in general, low (2-6\%), showing the lowest values in the case of A. maxima and I. galbana. This can be associated with lower protein content in these biomasses. As a result of the elemental analysis, the following average molecular formulae, in the exponential phase, were obtained for each species: $\mathrm{CH}_{1.93} \mathrm{O}_{1.61} \mathrm{~N}_{0.11} \mathrm{~S}_{0.02}$ (A. maxima), $\mathrm{CH}_{1.71} \mathrm{O}_{0.79} \mathrm{~N}_{0.07} \mathrm{~S}_{0.01}$ (C. vulgaris), $\mathrm{CH}_{1.61} \mathrm{O}_{0.60} \mathrm{~N}_{0.12} \mathrm{~S}_{0.01}$ (N. gaditana) and $\mathrm{CH}_{2.73} \mathrm{O}_{1.09} \mathrm{~N}_{0.09} \mathrm{~S}_{0.04}$ (I. galbana).

\subsection{Nutrients uptake}

Figure 4 shows nitrate consumption by each microalga. The results showed that all four species depleted most nitrate ( $>95 \%$ ) by day 7 of cultivation, what agrees with results found in the literature 
[40,41]. Cultivation media MC1 (for A. maxima) and MC4 (for N. gaditana and C. vulgaris) had a nitrate concentration of $134 \mathrm{mg} / \mathrm{L}$. In the individually optimised culture conditions, the above three species grew up to a biomass concentration of, approximately, $1 \mathrm{~g} / \mathrm{L}$. However, I. galbana in MC3 medium consumed $96 \mathrm{mg} / \mathrm{L}$ of nitrate to yield a similar amount of biomass, so that the nitrogen requirement for that microalga under the cultivation conditions was $28 \%$ lower than that needed by the other three species. Therefore, nitrogen is an essential nutrient acting as a limiting substrate in the cultivations. From the exponential growth phase and nitrate consumption (Fig. 4), the Monod parameters ( $\mu$ max and Ks) were calculated for all four species (Table 6) using equations 1 and 2.

Table 6. Monod parameters

\begin{tabular}{cccc}
\hline Species & $\mu_{\max }\left(\mathrm{d}^{-1}\right)$ & $\mathrm{K}_{\mathrm{S}}(\mathrm{mg} / \mathrm{L})$ & $\mathrm{Y}_{\mathrm{x} / \mathrm{s}}(\mathrm{g} / \mathrm{g})$ \\
\hline A. maxima & $0.202 \pm 0.006$ & $1.7 \pm 0.8$ & $5.7 \pm 1.2$ \\
C. vulgaris & $0.27 \pm 0.02$ & $38 \pm 10$ & $6.9 \pm 0.7$ \\
N. gaditana & $0.145 \pm 0.003$ & $11.8 \pm 0.7$ & $8.0 \pm 0.7$ \\
I. galbana & $0.181 \pm 0.008$ & $4 \pm 2$ & $6.4 \pm 0.4$ \\
\hline
\end{tabular}

The growth kinetic parameters can be notably affected by culture conditions, including ambient conditions and type and concentration of nutrients [42]. Although the values of the maximum specific growth rate in similar experimental conditions have not been reported for A. maxima, the value achieved in this work $\left(\mu_{\max }=0.202 \pm 0.006 \mathrm{~d}^{-1}\right)$ is higher than that found for other Arthrospira species (A. platensis) cultivated in batch mode using a medium with similar salinity $\left(\mu_{\max }=0.1824 \mathrm{~d}^{-1}\right)$ [43]. For $C$. vulgaris, the value of $\mu_{\max }=0.27 \pm 0.02 \mathrm{~d}^{-1}$ was within the range $\left(0.25-0.32 \mathrm{~d}^{-1}\right)$ of other studies where that species was cultured in wastewaters supplemented with ammonium [11]. Similar values were measured for the microalgae I. galbana $\left(\mu_{\max }=0.145 \pm 0.003 \mathrm{~d}^{-1}\right)$ and $N$. gaditana $\left(\mu_{\max }=0.181 \pm 0.008\right.$ $\mathrm{d}^{-1}$ ). With respect the half-saturation parameter, the $K_{s}$ values showed a high affinity of each microorganism for nitrate, especially in the case of A. maxima and N. gaditana, whose low value $(1.7 \pm 0.8 \mathrm{mg} / \mathrm{L}$ and $4 \pm 2 \mathrm{mg} / \mathrm{L}$, respectively). This means that both species can be very efficient to deplete nitrates from culture media up to very low concentrations. For C. vulgaris (Ks $=38 \pm 9 \mathrm{mg} / \mathrm{L}$ ) and I. galbana $\left(\mathrm{K}_{\mathrm{s}}=11.8 \pm 0.7 \mathrm{mg} / \mathrm{L}\right)$ the half-saturation constants, although higher than those measured for the other two studied species, are low enough to achieve a good nitrate removal efficiency, showing similar values than those reported in the literature for nitrate as limiting nutrient [21].

To evaluate other essential nutrients, the consumption of oligoelements was monitored in the culture media for 7 days (Fig. 5). All microalgae consumed all iron present in the culture media in a few days. I. galbana needed a larger amount of iron $(70 \mathrm{mg} / \mathrm{L})$ compared with the rest of the species (approximately $20 \mathrm{mg} / \mathrm{L}$ ). In the case of microalgae cultivated in fresh water, a notable consumption of iron was observed, with $28 \%$ and $12 \%$ of iron remaining unused in the case C. vulgaris and $N$. gaditana, respectively. However, these microalgae have a total consumption of nitrate leaving some iron present in the culture media. Marine microalgae completely consumed copper, whereas in the case of freshwater species it was not significantly depleted. The presence of boron in marine species also decreased. 


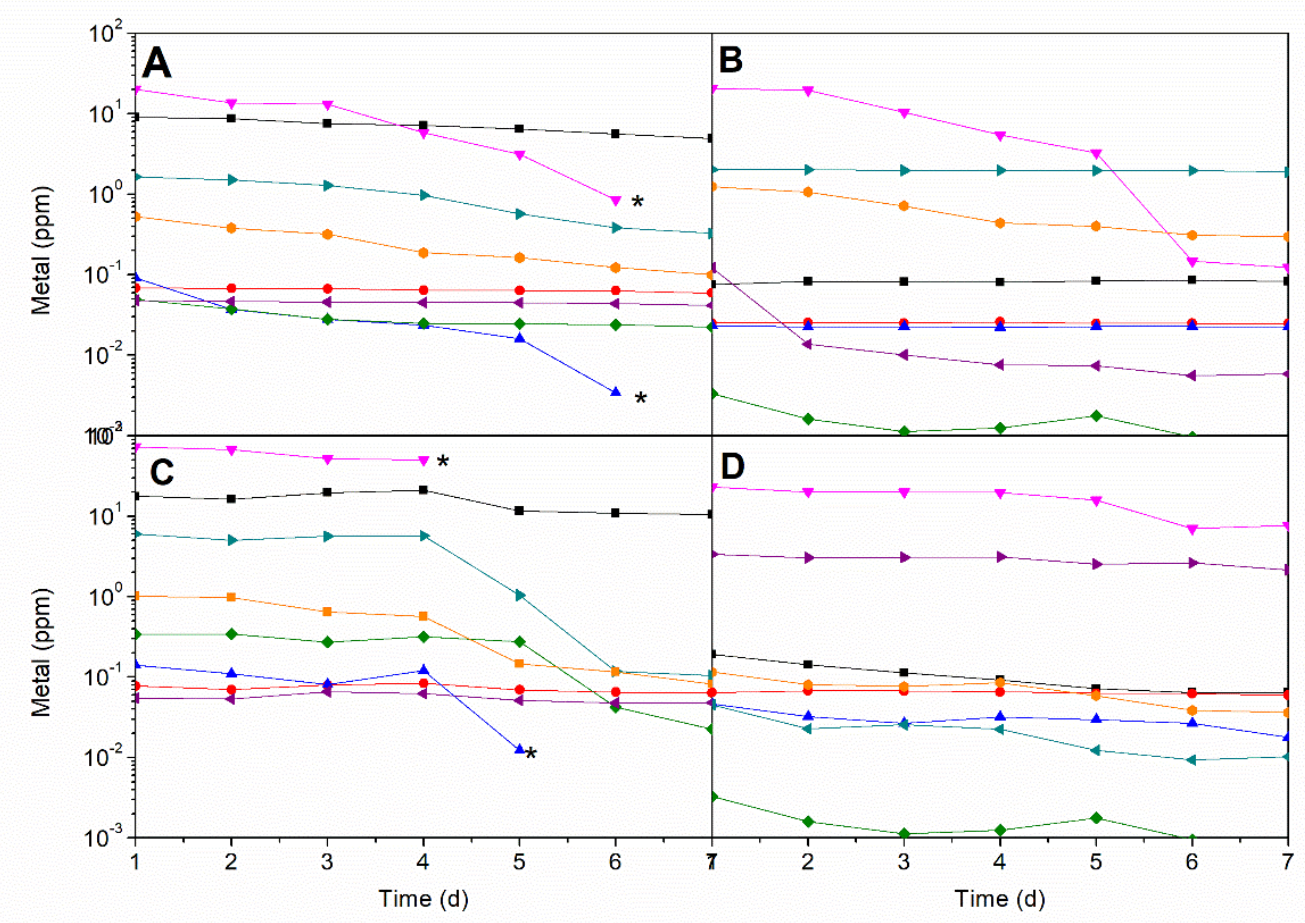

Figure 5. Oligoelement uptake during optimum growth of A. maxima (a), C. vulgaris (b), I. galbana (c) and $N$. gaditana $(\mathrm{d})\left(\bullet \mathrm{B}, \bullet \mathrm{Co}, \Delta \mathrm{Cu}, \nabla \mathrm{Fe}, \bullet \mathrm{Mn}, \triangleleft \mathrm{Mo}, \nabla \mathrm{P}, \square \mathrm{Zn},{ }^{*}\right.$ not detected at higher times).

\subsection{Growth in wastewaters}

All microalgae and cyanobacterium studied were able to grow in wastewaters (Table 1) maintaining the inoculum:culture medium ratio of 5:45 and a light photoperiod 12:12, obtaining similar biomass production in the three non-sterilized wastewater samples (AD1, AD2 and AD3) (Figure 6). The above four species were capable of developing in non-specific media as long as they have a certain content of salts in the culture medium that promotes metabolic development, this is due to the metals that present wastewater serve as essential trace elements for the development of these species.

To evaluate the consumption of nutrients from wastewater, the analysis of the cultures carried out in AD2 was carried out, because the growth curves were similar in media AD1, AD2 and AD3. Generally, most of the nitrogen coming from sewage water is in the form of ammonium, nitrite or nitrates. Initially, it is usually found as ammonium and it is converted into nitrites and nitrates after a conventional biological treatment in the presence of nitrifying bacteria in a $24-\mathrm{h}$ period. Once the nitrogen is in the form of nitrate, it can be uptake by the microalgae to proceed to the bioremediation of the water [44]. The nitrate content of the water sample at the outlet of the separator after the biological treatment (AD2) is $6.9 \mathrm{ppm}$. This low level of nitrate concentration may be due to the fact that in the biological separator certain bacteria are fed by this nutrient. The results showed a significant decrease of nitrates with microalgae C. vulgaris, I. galbana and N. gaditana up to 1-2 ppm, thus consuming $70-80 \%$ of the total. On the contrary, in the case of cyanobacterium, A. maxima only reached a consumption of about $30 \%$. This low nitrate depletion efficiency may be due to the need of longer photoperiod to increase the assimilation [45]. 


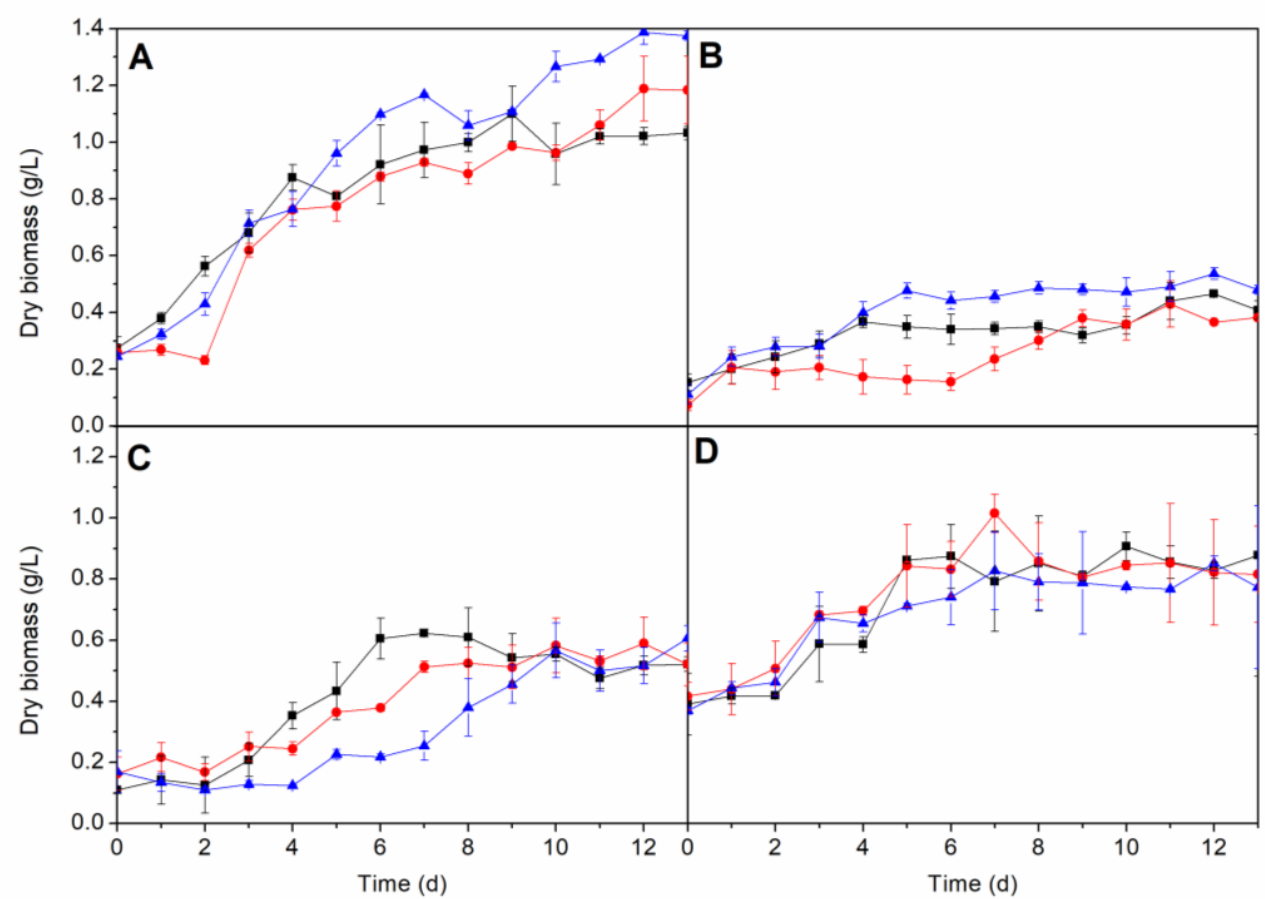

Figure 6. Growth of A. maxima (a), C. vulgaris (b), I. galbana (c) and N. gaditana (d) with different wastewater ( $\mathrm{AD} 1, \bullet \mathrm{AD} 2, \triangle \mathrm{AD} 3)$.

Despite the low concentration of nitrates in the culture medium, their low uptake can be caused by of another limiting nutrient. There is a clear decrease in phosphorus in the culture medium $(>90 \%)$, while the rest of the elements present in the medium are consumed to a lesser extent (data not shown). This may be due to the fact that these metals are needed in very low amounts for the metabolic development of these species. All this seems to indicate that in these wastewaters both nitrates and phosphorus, as well as the light photoperiod, must keep an optimum ratio to achieve a complete depletion of both nutrients [46,47].

In summary, the effect of cultivation variables on the growth of three microalgae and one cyanobacterium with potential industrial interest have been evaluated. Whereas the initial inoculum volume does not affect the final biomass production, the amount of light to which the microalgae are exposed is a significant factor. Thus, the photoperiod 12:12 $\mathrm{h}$ light:darkness is the most favourable for the growth of the three species The analysis of biomass composition showed that for A. maxima and I. galbana, the protein content increased during the exponential phase while for N. gaditana and C. vulgaris, the accumulation of proteins ended before the stationary phase was reached. The nitrates and iron, as macro- and micro-nutrient respectively, became the limiting compounds for all four species, being copper essential for growing in marine media. Although all four species were able to grow in wastewaters, I. galbana, N. gaditana and C. vulgaris achieved higher nitrogen removal capacity than cyanobacterium A. maxima.

\section{Materials and Methods}

\subsection{Microorganism}


Arthrospira maxima (SAG 49.88), Chlorella vulgaris (SAG 211.11-b), Isochrysis galbana (SAG 13.92) and Nannochloropsis gaditana (SAG 2.99) strains were obtained from the SAG Culture Collection of Algae (University of Gottingen, Germany).

\subsection{Growth experiments}

Microalgae cultivations were carried out in in $50 \mathrm{~mL}$ batch mini-photobioreactors where atmospheric air was continuously bubbling and in-line sterilized through a $45 \mu \mathrm{m}$ membrane filter (23). Air flow was provided only during light periods at a rate of $3.5 \mathrm{~L} / \mathrm{min}$. The inoculum:culture media ratios used in this work were 5:45, 10:40, 15:45 and 20:30 mL. We tested three different light:darkness photoperiods: 12:12 h, 6:18 h and 18:6 h, using discontinuous artificial illumination provided by $12 \mathrm{~V} / 24 \mathrm{~W}$ white LED lamps under an irradiance of $108 \mu \mathrm{mol} \cdot$ photons $/ \mathrm{m}^{2} \cdot \mathrm{s}^{1}$.

Each species was cultivated in two different synthetic nutrient media: Guillard's F/2 (EasyAlgae. Cádiz, Spain) and Walne's (Aqualgae. A Coruña, Spain), both in fresh and seawater. Synthetic seawater was produced with CoralMarine EasyMix (GroTech GmbH. Langenhansen, Germany). Microalgae were also cultivated in waters withdrawn from different stages of Rey Juan Carlos University waste water treatment plant located in its Campus in Mostoles (Madrid, Spain). Table 1 shows the identification of each cultivation media and the composition of the wastewater is shown in Table S1.

The microalgae and cyanobacteria were allowed to grow for two weeks at $25^{\circ} \mathrm{C}$. The optical density of the culture was measured using a V-630 spectrophotometer (Jasco Analitica Spain, Madrid, Spain) at $540 \mathrm{~nm}$. To determine the dry biomass content, a calibration with biomass from the stationary phase was performed to establish the absorbance-dry weight relationship. For this purpose, a homogeneous sample of the culture was centrifuged at $5000 \mathrm{rpm}$ for $5 \mathrm{~min}$ and then the solid phase containing biomass was dried at $105^{\circ} \mathrm{C}$ overnight and allowed to cool down to room temperature inside a desiccator to obtain the weight of dry microalgae. The $\mathrm{pH}$ was measured every day with a Basic 30 pHmeter (Crison Instruments. Barcelona, Spain).

Once the culture conditions had been optimised in the mini-photobioreactors, the process was scaled to a $12 \mathrm{~L}$ photobioreactor (adapted BioFlo 110 fermenter/bioreactor. New Brunswick Scientific. Edison, NJ, USA) to fully characterised the microalgal biomass as a function of time and state of growth of the microalgae.

\subsection{Analysis of biomass}

The microalga cells were lysed by lysis buffer under vortex stirring for $5 \mathrm{~min}$ and total and soluble protein contents were measured by the Bradford method (24). The protein concentration was then measured spectrophotometrically in a V-630 spectrophotometer (Jasco Analitica. Madrid, Spain) using bovine serum albumin as standard protein to build the calibration curve.

The carbohydrate content was measured by the DuBois method (25) using glucose as calibration standard. The carbohydrate soluble fraction was measured from lysed cells suspension using a DNS solution (1 $\mathrm{g}$ of 3,5-dinitrosalicylic acid, $30 \mathrm{~g}$ of sodium potassium tartrate tetrahydrate, $50 \mathrm{~mL}$ of water and $20 \mathrm{~mL} 2 \mathrm{~N} \mathrm{NaOH}$ ). The procedure was as follows: $1 \mathrm{~mL}$ of each sample and each calibration solution was placed in a test tube. Then, $1 \mathrm{~mL}$ of DNS was added, and the resulting solution was vortexed, heated in a water bath at $100^{\circ} \mathrm{C}$ for $10 \mathrm{~min}$ and cooled by quenching in ice. Finally, $10 \mathrm{~mL}$ of distilled water were added, and the solution was measured with a V-630 spectrophotometer at 540 $\mathrm{nm}$.

Elemental analysis was performed in a Vario EL III CHNS (Elementar Analysensysteme. Langenselbold, Germany) to quantify the amount of carbon, hydrogen, nitrogen, and sulfur in the microalgae and the oxygen amount was calculated by mass balance Around $10 \mathrm{mg}$ of dry biomass were weighted and fully oxidized in an air stream at $1000^{\circ} \mathrm{C}$. Then, the oxidation products were transported by a carrier gas (helium) through selective adsorption columns. The gases were then measured with a thermal conductivity detector. Sulphanilic acid was used as standard for element quantification. 
The lipids were extracted using a chloroform:methanol $(4 / 5 \mathrm{v} / \mathrm{v})$ solvent mixture and the lipid concentration was calculated gravimetrically [48]. Nitrate content was measured using a polymermembrane selective electrode (Metrohm. Herisau, Switzerland). The depletion of metals and other oligoelements during microalga growth was monitored by induced plasma atomic emission spectroscopy (ICP-AES) on a Vista AX CCD simultaneous ICP-AES (Varian. Palo Alto, CA, USA). All analysis were performed in triplicate to allow calculation of average values and standard errors of each measurement.

\subsection{Growth kinetics}

Biomass growth and nutrient removal was monitored as described above and that information was used to model the specific growth rate $(\mu)$ following a first-order kinetics (equation 1 ) assuming a Monod-type kinetics with nitrate as limiting nutrient (equation 2).

$$
\begin{gathered}
\mu=\frac{1}{X} \frac{d X}{d t}, \\
\mu=\mu_{\max } \frac{S}{K_{S}+S},
\end{gathered}
$$

where $X$ is the biomass concentration in dry basis $(g / L), S$ the nitrate concentration $(\mathrm{mg} / \mathrm{L}), \mu$ max the maximum specific growth rate $\left(\mathrm{d}^{-1}\right)$ and $\mathrm{Ks}$ the half-saturation constant $(\mathrm{mg} / \mathrm{L})$. Therefore, the kinetic parameters $\mu \max$ and $\mathrm{Ks}$ can be calculated from the monitoring of growth and nitrate consumption with time during the exponential phase, assuming that the specific growth rate is constant during this phase. Growth and nitrate uptake are also related through the corresponding yield coefficient (Yx/s, equation 3) which gives the amount of biomass produced by unit mass of nitrate consumed by the microorganism.

$$
Y_{X / S}=-\frac{\Delta X}{\Delta S}
$$

\section{Conclusions}

The effect of cultivation variables on the growth of three microalgae and one cyanobacterium with potential industrial interest have been evaluated. Whereas the initial inoculum volume does not affect the final biomass production, the amount of light to which the microalgae are exposed is a significant factor. Thus, the photoperiod 12:12 $\mathrm{h}$ light:darkness is the most favourable for the growth of the three species The analysis of biomass composition showed that for A. maxima and I. galbana, the protein content increased during the exponential phase while for N. gaditana and C. vulgaris, the accumulation of proteins ended before the stationary phase was reached. The nitrates and iron, as macro- and micro-nutrient respectively, became the limiting compounds for all four species, being copper essential for growing in marine media. Although all four species were able to grow in wastewaters, I. galbana, N. gaditana and C. vulgaris achieved higher nitrogen removal capacity than cyanobacterium A. maxima.

Supplementary Materials: The following are available online, Table S1: Characterisation of water samples from wastewater treatment plant located at Campus of Móstoles (Universidad Rey Juan Carlos), Table S2: Elemental composition (\%) of A. maxima at different times, Table S3: Elemental composition (\%) of C. vulgaris at different times, Table S4: Elemental composition (\%) of N. gaditana at different times, Table S5: Elemental composition (\%) of I. galbana at different times, Figure S1: Nitrate uptake in wastewater AD2.

Author Contributions: L.F.B. and G.V. devised the experimental work, analysed the tests and wrote the final version of the manuscript. A.S.B. performed the experimental work experiments, sample characterization and 
made a first draft of the manuscript. V.M. and R.R. analysed and discussed the results. The listed authors have contributed substantially to this work.

Funding: The authors acknowledge the support from INSPIRA1 project (S2013/ABI-2783) financed by Comunidad de Madrid and co-financed by FEDER “A way of making Europe".

Conflicts of Interest: The authors declare no conflict of interest.

\section{References}

1. Guiry, M.D. How many species of algae are there? J. Phycol. 2012, 48, 1057-1063.

2. Carrieri, D.; Ananyev, G.; Brown, T.; Dismukes, G.C. In vivo bicarbonate requirement for water oxidation by Photosystem II in the hypercarbonate-requiring cyanobacterium Arthrospira maxima. J. Inorg. Biochem. 2007, 101, 1865-1874.

3. Gutiérrez-Rebolledo, G.A.; Galar-Martínez, M.; García-Rodríguez, R.V.; Chamorro-Cevallos, G.A.; Hernández-Reyes, A.G.; Martínez-Galero, E. Antioxidant Effect of Spirulina (Arthrospira) maxima on Chronic Inflammation Induced by Freund's Complete Adjuvant in Rats. J. Med. Food 2015, 18, 865-871.

4. Salati, S.; D’Imporzano, G.; Menin, B.; Veronesi, D.; Scaglia, B.; Abbruscato, P.; Mariani, P.; Adani, F. Mixotrophic cultivation of Chlorella for local protein production using agro-food by-products. Bioresour. Technol. 2017, 230, 82-89.

5. Fawley, K.P.; Fawley, M.W. Observations on the Diversity and Ecology of Freshwater Nannochloropsis (Eustigmatophyceae), with Descriptions of New Taxa. Protist 2007, 158, 325-336.

6. Scholz, M.J.; Weiss, T.L.; Jinkerson, R.E.; Jing, J.; Roth, R.; Goodenough, U.; Posewitz, M.C.; Gerken, H.G. Ultrastructure and composition of the Nannochloropsis gaditana cell wall. Eukaryot. Cell 2014, 13, 1450-1464.

7. Mendoza, A.; Vicente, G.; Bautista, L.F.; Morales, V. Opportunities for Nannochloropsis gaditana biomass through the isolation of its components and biodiesel production. Green Process. Synth. 2015, 4, 97-102.

8. Sánchez, Á.; Maceiras, R.; Cancela, Á.; Pérez, A. Culture aspects of Isochrysis galbana for biodiesel production. Appl. Energy 2013, 101, 192-197.

9. Bautista, L.F.; Vicente, G.; Mendoza, A.; González, S.; Morales, V. Enzymatic Production of Biodiesel from Nannochloropsis gaditana Microalgae Using Immobilized Lipases in Mesoporous Materials. Energy and Fuels 2015, 29, 4981-4989.

10. Park, C.; Lee, J.H.; Yang, X.; Yoo, H.Y.; Lee, J.H.; Lee, S.K.; Kim, S.W. Enhancement of hydrolysis of Chlorella vulgaris by hydrochloric acid. Bioprocess Biosyst. Eng. 2016, 39, 1015-1021.

11. Mendez, L.; Sialve, B.; Tomás-Pejó, E.; Ballesteros, M.; Steyer, J.P.; González-Fernández, C. Comparison of Chlorella vulgaris and cyanobacterial biomass: cultivation in urban wastewater and methane production. Bioprocess Biosyst. Eng. 2016, 39, 703-712.

12. Khetkorn, W.; Rastogi, R.P.; Incharoensakdi, A.; Lindblad, P.; Madamwar, D.; Pandey, A.; Larroche, C. Microalgal hydrogen production - A review. Bioresour. Technol. 2017, 243, 1194-1206.

13. Harun, R.; Singh, M.; Forde, G.M.; Danquah, M.K. Bioprocess engineering of microalgae to produce a variety of consumer products. Renew. Sustain. Energy Rev. 2010, 14, 1037-1047.

14. Jorquera, O.; Kiperstok, A.; Sales, E.A.; Embiruçu, M.; Ghirardi, M.L. Comparative energy life-cycle analyses of microalgal biomass production in open ponds and photobioreactors. Bioresour. Technol. 2010, 101, 1406-1413.

15. Allen, J.F. State Transitions--a Question of Balance. Science (80). 2003, 299, 1530-1532.

16. Camacho-Rodríguez, J.; Cerón-García, M.C.C.; González-López, C.V. V; Fernández-Sevilla, J.M.M.; Contreras-Gómez, A.; Molina-Grima, E. A low-cost culture medium for the production of Nannochloropsis gaditana biomass optimized for aquaculture. Bioresour. Technol. 2013, 144, 57-66. 
17. Picardo, M.C.; de Medeiros, J.L.; Araújo, O. de Q.F.; Chaloub, R.M. Effects of $\mathrm{CO}_{2}$ enrichment and nutrients supply intermittency on batch cultures of Isochrysis galbana. Bioresour. Technol. 2013, 143, 242-50.

18. Walne, P.R. Studies on the Food Value of Nineteen Genera of Algae to Juvenile Bivalves of the Genera Ostrea, Crassostrea, Mercenaria and Mytilus. Fish. Invest., 1970, 26, 1-62.

19. R.R.L. Guillard; J.H. Ryther Studies on Marine Planktonic Diatoms I. Cyclotella nana Hustedt and Detonula confervacea (Cleve). Can. J. Microbiol. 1962, 8, 229-239.

20. Hwang, J.-H.; Church, J.; Lee, S.-J.; Park, J.; Lee, W.H. Use of Microalgae for Advanced Wastewater Treatment and Sustainable Bioenergy Generation. Environ. Eng. Sci. 2016, 33, 882-897.

21. Lee, E.; Jalalizadeh, M.; Zhang, Q. Growth kinetic models for microalgae cultivation: A review. Algal Res. 2015, 12, 497-512.

22. Georgianna, D.R.; Mayfield, S.P. Exploiting diversity and synthetic biology for the production of algal biofuels. Nature 2012, 488, 329-335.

23. Gonçalves, A.L.; Pires, J.C.M.; Simões, M. The effects of light and temperature on microalgal growth and nutrient removal: an experimental and mathematical approach. RSC Adv. 2016, 6, 22896-22907.

24. Vanags, J.; Kunga, L.; Dubencovs, K.; Galvanauskas, V.; Grīgs, O. Influence of Light Intensity and Temperature on Cultivation of Microalgae Desmodesmus communis in Flasks and Laboratory-Scale Stirred Tank Photobioreactor. Latv. J. Phys. Tech. Sci. 2015, 52, 59-70.

25. Jacob-Lopes, E.; Scoparo, C.H.G.; Lacerda, L.M.C.F.; Franco, T.T. Effect of light cycles (night/day) on CO $\mathrm{CO}_{2}$ fixation and biomass production by microalgae in photobioreactors. Chem. Eng. Process. Process Intensif. 2009, 48, 306-310.

26. Fábregas, J.; Maseda, A.; Domínguez, A.; Ferreira, M.; Otero, A. Changes in the cell composition of the marine microalga, Nannochloropsis gaditana, during a light:dark cycle. Biotechnol. Lett. 2002, 24, 1699-1703.

27. Simionato, D.; Sforza, E.; Corteggiani Carpinelli, E.; Bertucco, A.; Giacometti, G.M.; Morosinotto, T. Acclimation of Nannochloropsis gaditana to different illumination regimes: Effects on lipids accumulation. Bioresour. Technol. 2011, 102, 6026-6032.

28. Xueqin, W.; Pei, Z.; Ping, H.; Lili, P.; Lei, H.; Chu, C.; Linglin, L.; Rong, Z. Optimization of Cultural Conditions of Isochrysis galbana Parks 3011 and Its Mass-cultural. Food Sci. 2006, 27, 253-258.

29. Rocha, J.M.S.; Garcia, J.E.C.; Henriques, M.H.F. Growth aspects of the marine microalga Nannochloropsis gaditana. Biomol. Eng. 2003, 20, 237-242.

30. dos Santos, R.R.; Araújo, O. de Q.F.; de Medeiros, J.L.; Chaloub, R.M. Cultivation of Spirulina maxima in medium supplemented with sugarcane vinasse. Bioresour. Technol. 2016, 204, 38-48.

31. Valenzuela-Espinoza, E.; Millán-Núñez, R.; Núñez-Cebrero, F.; Valenzuela-Espinoza, E.; Millan-Nunez, R.; Nunez-Cebrero, F. Protein, carbohydrate, lipid and chlorophyll a content in Isochrysis aff. galbana (clone TIso) cultured with a low cost alternative to the f/2 medium. Aquac. Eng. 2002, 25, 207-216.

32. Colla, L.M.; Oliveira Reinehr, C.; Reichert, C.; Costa, J.A.V. Production of biomass and nutraceutical compounds by Spirulina platensis under different temperature and nitrogen regimes. Bioresour. Technol. 2007, 98, 1489-1493.

33. Sassano, C.E.N.; Gioielli, L.A.; Ferreira, L.S.; Rodrigues, M.S.; Sato, S.; Converti, A.; Carvalho, J.C.M. Evaluation of the composition of continuously-cultivated Arthrospira (Spirulina) platensis using ammonium chloride as nitrogen source. Biomass and Bioenergy 2010, 34, 1732-1738.

34. Zarrouk, C. Contribution a l'etude d'une cyanobacterie: influence de divers facteurs physiques et chimiques sur la croissance et la photosynthese de Spirulina maxima (Setchell et Gardner) Geitler. Ph.D. Thesis, University of Paris, France, 1966. 
35. Walach, M.R.; Bazin, M.J.; Pirt, S.J.; Balyuzi, H.H.M. Computer control of carbon-nitrogen ratio in Spirulina platensis. Biotechnol. Bioeng. 1987, 29, 520-528.

36. Postma, P.R.; Suarez Garcia, E.; Safi, C.; Yonathan, K.; Olivieri, G.; Barbosa, M.J.; Wijffels, R.H.; Eppink, M.H.M. Energy efficient bead milling of microalgae: Effect of bead size on disintegration and release of proteins and carbohydrates. Bioresour. Technol. 2016.

37. Gim, G.H.; Ryu, J.; Kim, M.J.; Kim, P. Il; Kim, S.W. Effects of carbon source and light intensity on the growth and total lipid production of three microalgae under different culture conditions. J. Ind. Microbiol. Biotechnol. 2016, 43, 605-616.

38. Halim, R.; Danquah, M.K.; Webley, P.A. Extraction of oil from microalgae for biodiesel production: A review. Biotechnol. Adv. 2012, 30, 709-732.

39. Xu, Y.; Boeing, W.J. Modeling maximum lipid productivity of microalgae: Review and next step. Renew. Sustain. Energy Rev. 2014, 32, 29-39.

40. Paes, C.R.P.S.; Faria, G.R.; Tinoco, N.A.B.; Castro, D.J.F.A.; Barbarino, E.; Lourenco, S.O. Growth, nutrient uptake and chemical composition of Chlorella sp. and Nannochloropsis oculata under nitrogen starvation. Lat. Am. J. Aquat. Res. 2016, 44, 275-292.

41. Whitton, R.; Le Mével, A.; Pidou, M.; Ometto, F.; Villa, R.; Jefferson, B. Influence of microalgal N and P composition on wastewater nutrient remediation. Water Res. 2016, 91, 371-378.

42. Xin, L.; Hong-ying, H.; Ke, G.; Ying-xue, S. Effects of different nitrogen and phosphorus concentrations on the growth, nutrient uptake, and lipid accumulation of a freshwater microalga Scenedesmus sp. Bioresour. Technol. 2010, 101, 5494-5500.

43. Ravelonandro, P.H.; Ratianarivo, D.H.; Joannis-Cassan, C.; Isambert, A.; Raherimandimby, M. Improvement of the growth of Arthrospira (Spirulina) platensis from Toliara (Madagascar): Effect of agitation, salinity and $\mathrm{CO}_{2}$ addition. Food Bioprod. Process. 2011, 89, 209-216.

44. Ji, M.; Abou-shanab, R.A.I.; Hwang, J.; Timmes, T.C.; Kim, H.; Ph, D.; Oh, Y.; Jeon, B. Removal of Nitrogen and Phosphorus from Piggery Wastewater Effluent Using the Green Microalga Scenedesmus obliquus. J. Environ. Eng. 2013, 139, 1198-1205.

45. Wuang, S.C.; Khin, M.C.; Chua, P.Q.D.; Luo, Y.D. Use of Spirulina biomass produced from treatment of aquaculture wastewater as agricultural fertilizers. Algal Res. 2016, 15, 59-64.

46. Raeesossadati, M.J.J.; Ahmadzadeh, H.; McHenry, M.P.P.; Moheimani, N.R.R. CO2 bioremediation by microalgae in photobioreactors: Impacts of biomass and $\mathrm{CO}_{2}$ concentrations, light, and temperature. Algal Res. 2014, 6, 78-85.

47. Novoveská, L.; Zapata, A.K.M.; Zabolotney, J.B.; Atwood, M.C.; Sundstrom, E.R. Optimizing microalgae cultivation and wastewater treatment in large-scale offshore photobioreactors. Algal Res. 2016, 18, 86-94.

48. Breuer, G.; Evers, W. a. C.; de Vree, J.H.; Kleinegris, D.M.M.; Martens, D.E.; Wijffels, R.H.; Lamers, P.P. Analysis of Fatty Acid Content and Composition in Microalgae. J. Vis. Exp. 2013, 1, 1-9. 